\title{
In vitro synergistic activity of colistin and teicoplanin combination against multidrug-resistant Acinetobacter spp
}

\author{
Osama Mohamed Samy Mohamed Rady ${ }^{1} \cdot$ Laila El-Attar $^{1} \cdot$ Amira Amine $^{1}{ }^{1}$
}

Received: 18 October 2021 / Revised: 1 November 2021 / Accepted: 12 December 2021 / Published online: 28 January 2022

(c) The Author(s) 2022. This article is published with open access

\begin{abstract}
Drug combinations may have a crucial role in treating infections due to multidrug resistant Acinetobacter spp. One suggested combination is colistin with teicoplanin. The effect of colistin on Acinetobacter spp. outer membrane can permit teicoplanin to its target in the cell wall. The aim of this study was to evaluate the synergistic activity of colistin and teicoplanin combination against 29 multidrug resistant isolates of Acinetobacter spp. The antimicrobial activity of colistin alone and in combination with teicoplanin was assessed using MIC and time-kill assays. The combination of 1 $\mathrm{mg} / \mathrm{l}$ colistin and $10 \mathrm{mg} / \mathrm{l}$ teicoplanin showed in vitro synergism against all tested Acinetobacter isolates except one (Acinetobacter lowffii). The combination of $1 \mathrm{mg} / \mathrm{l}$ colistin and $10 \mathrm{mg} / \mathrm{l}$ teicoplanin was bactericidal at $6 \mathrm{~h}$ against $100 \%$ of Acinetobacter baumannii isolates with no bacterial regrowth at $24 \mathrm{~h}$. The same combination was bactericidal against three out of seven non-baumannii Acinetobacter isolates. The increased concentration of teicoplanin $(20 \mathrm{mg} / \mathrm{l}) \mathrm{was}$ synergistic but still not bactericidal against the four remaining isolates. The combination of colistin and teicoplanin was synergistic against all tested Acinetobacter spp It is therefore recommended that clinical trials are conducted to clarify the therapeutic potential of the combination.
\end{abstract}

\section{Introduction}

Acinetobacter species (spp.) has emerged in recent years as one of the opportunistic healthcare associated pathogens. Acinetobacter baumannii (A. baumannii) is the most frequently encountered spp, but other Acinetobacter spp. are also frequently isolated. Acinetobacter spp. is particularly problematic in intensive care units infections and is linked to high morbidity and mortality as well as extended hospital stays. This is coupled with the increase in infections due to multidrug-resistant (MDR) A. baumannii and extensively drug-resistant (XDR) and pandrug-resistant (PDR) isolates that have also emerged. MDR is defined as strains resistant to at least one agent in three or more antimicrobial categories. XDR is defined as strains resistant to at least one agent in all but two or fewer antimicrobial categories. PDR is defined as those resistant to all agents in

Amira Amine

amiraamine@gmail.com

1 Microbiology Department, High Institute of Public Health, Alexandria University, Alexandria, Egypt all antimicrobial categories Traditionally, carbapenem antibiotics have been considered the final line of defense however, carbapenem resistant $A$. baumannii have disseminated worldwide $[1,2]$.

The emergence of strains resistant to all clinically used antibiotics has led to reliance on the polymyxins as a last resort. The International Consensus Guidelines on using the polymyxins has recommended that both colistin and polymyxin B be made available for the physician to have the flexibility to use either of them depending on the clinical situation. In vitro these antibiotics behave similarly and therefore we have used colistin in this study but expect that polymyxin B could behave similarly. Colistin remains an effective antibiotic against $A$. baumannii, however, colistin resistance in A. baumannii has been reported. Another problem associated with colistin is heteroresistance which raises concerns that colistin alone may lack sufficient killing activity to be used as a monotherapy. Thus, the use of combination therapy has been recommended as a potential strategy to boost bacterial killing and decrease the development of resistance in treatment of MDR A. baumannii infections [3]. One of the suggested combinations is colistin with the anti-gram positive antibiotics. such as the glycopeptide teicoplanin. The adjuvant permeabilizing effect of 
colistin on the outer membrane can allow teicoplanin to penetrate the cell and act by inhibiting cell wall synthesis in dividing organisms $[2,4]$.This study aimed to evaluate the synergistic activity of colistin and teicoplanin combination in vitro against Acinetobacter spp.

\section{Materials and methods}

\section{Bacterial isolates}

Twenty-nine Acinetobacter spp. isolates were collected from clinical microbiology laboratories and verified using MALDITOF MS (Autoflex, Bruker Daltonics, Germany). Fifty percent of bacterial isolates were collected from respiratory samples (30\% from bronchial lavage and 20\% from sputum), $26.6 \%$ from blood, $10 \%$ from pus swabs, $6.7 \%$ of each of urine and environmental samples.

Twenty-two of the identified isolates were A. baumannii, 4 Acinetobacter nosocomialis (A. nosocomialis) isolates and one of each of Acinetobacter lwoffii (A. lowffii), Acinetobacter junii (A. junii) and Acinetobacter haemolyticus (A. haemolyticus).

\section{Antimicrobial susceptibility testing}

Susceptibility patterns of all isolates were tested using a panel of 13 antibiotics including, piperacillin, piperacillintazobactam, ampicillin- sulbactam, ceftazidime, ceftriaxone, imipenem, meropenem, gentamicin, tobramycin, amikacin, doxycycline, ciprofloxacin, levofloxacin, and trimethoprimsulphmethoxazole [5].

\section{Colistin MICs determination}

Colitin MICs were determined using commercial kit ComASP $^{\mathrm{TM}}$ Colistin $\left(\right.$ Liofilchem $^{\circledR}$ ) for the 29 identified bacterial isolates [6]. Breakpoints were interpreted according to CLSI 2019 [5].

\section{Time-kill assays}

Time-kill assays were performed using colistin sulfate at a concentration of $1 \mathrm{mg}^{-1}$ and teicoplanin at $10 \mathrm{mg} \mathrm{l}^{-1}$. Bactericidal activity was defined as a three-fold log reduction in cell numbers compared with the starting inoculum. Synergy was defined as a $\geq 2$-fold $\log$ reduction in cell numbers at $24 \mathrm{~h}$ when compared to the most active agent used alone [7].

Bacterial isolates that the combination of colistin $1 \mathrm{mg}^{-1}$ and teicoplanin $10 \mathrm{mg} \mathrm{l}^{-1}$ was not bactericidal and/or synergistic against were tested again using the combination of colistin $1 \mathrm{mg} \mathrm{l}^{-1}$ and teicoplanin $20 \mathrm{mg}^{-1}$.
Table 1 Distribution of the 29 bacterial isolates according to their susceptibility to colistin

\begin{tabular}{|c|c|c|c|c|c|c|c|}
\hline \multirow[t]{3}{*}{ Isolates } & \multicolumn{7}{|c|}{ Colisitn MICs $\left(\mu \mathrm{g} \mathrm{ml}^{-1}\right)$} \\
\hline & \multicolumn{4}{|c|}{$\begin{array}{l}\text { Colistin susceptible MICs } \\
\leq 2 \mu \mathrm{g} \mathrm{ml}^{-1}\end{array}$} & \multicolumn{3}{|c|}{$\begin{array}{l}\text { Colistin resistant } \\
\text { MICs }>2 \mu \mathrm{gl}^{-1}\end{array}$} \\
\hline & 0.25 & 0.5 & 1 & 2 & 4 & 8 & 16 \\
\hline A. baumannii (22) & 13 & 6 & 1 & - & 2 & - & - \\
\hline A. nosocomails (4) & 2 & - & - & - & - & 2 & - \\
\hline A. lowffii (1) & - & - & - & - & 1 & - & - \\
\hline A. junii (1) & - & - & - & 1 & - & - & - \\
\hline A. hemolyticus (1) & 1 & - & - & - & - & - & - \\
\hline \multirow[t]{2}{*}{ Total } & 17 & 6 & 1 & 1 & 3 & 2 & - \\
\hline & 24 & & & & & 5 & \\
\hline
\end{tabular}

\section{Results and discussion}

All the tested isolates were $100 \%$ resistant to ceftriaxone and ceftazidime. For the other tested antibiotics the bacterial isolates showed resistance ranging from $33.33 \%$ to $96 \%$. According to their pattern of resistance to tested antibiotics, 15 isolates were found to be MDR (51.7\%), 11 XDR (37.9\%) and 3 PDR (10.3\%). Five of the tested isolates showed resistance to colistin, these were 2 of each $A$. baumannii and A. nosocomialis and one of Acinetobacter lowffii (A lowffii) (Table 1).

Colistin's bactericidal activity against Acinetobacter spp. is concentration-dependent, and an average plasma concentration of $2 \mu \mathrm{g} \mathrm{ml}^{-1}$ colistin has been proposed as a for isolates with MICs of $\leq 1 \mu \mathrm{g} \mathrm{ml}^{-1}$. However, this is difficult to achieve clinically [8]. So, in the present study colistin was tested in concentration of $1 \mathrm{mg} \mathrm{l}^{-1}$ to make it more clinically relevant. Since colistin is already nephrotoxic, teicoplanin was selected instead of vancomycin as it has lower nephrotoxicity so the combination can be more clinically relevant. Teicoplanin optimal therapeutic plasma concentration is suggested to range from $\geq 10 \mu \mathrm{g} \mathrm{ml}^{-1}$ to $\geq 20 \mu \mathrm{g} \mathrm{ml}^{-1}$ [9], and the lower concentration of teicoplanin $\left(10 \mathrm{mg}^{-1}\right)$ was used in this study.

Colistin and teicoplanin combination was tested against 29 tested Acinetobacter spp. isolates. This combination was synergistic and bactericidal against the 22 tested $A$. baumannii isolates. Previous studies have examined synergism between colistin and teicoplanin, however a smaller number of isolates were used, and the optimum concentration of each antibiotic was not defined, as different methods and the difference in the clonality of isolates resulted in different outcomes. To our knowledge, there are no previous studies that tested the combination on non- A. baumannii isolates, while the present study included 7 isolates (Table 2).

Wareham et al. tested the combination on five MDR colistin- susceptible isolates of A. baumannii, however we used a lower concentration of teicoplanin $\left(10 \mathrm{mg} \mathrm{l}^{-1}\right)$ [4]. 
Table 2 Colistin sensitivity and synergy testing with teicoplanin

\begin{tabular}{|c|c|c|c|c|}
\hline \multirow[t]{2}{*}{ Strain (number) } & \multirow[t]{2}{*}{ Colistin MIC mg/l } & \multicolumn{3}{|l|}{ Time to kill assay } \\
\hline & & Colistin $1 \mathrm{mg}^{-1}$ & $\begin{array}{l}\text { Colistin } 1 \mathrm{mg}^{-1} \text { and teicoplanin } 10 \\
\mathrm{mg} \mathrm{l}^{-1}\end{array}$ & $\begin{array}{l}\text { Colistin } 1 \mathrm{mg} \mathrm{l}^{-1} \text { and teicoplanin } \\
20 \mathrm{mg} \mathrm{l}^{-1}\end{array}$ \\
\hline A. baumannii (20) & $0.25-1$ & $\begin{array}{l}\text { Sensitive, regrowth } \\
\text { after } 24 \mathrm{~h}\end{array}$ & $\begin{array}{l}\text { Bactericidal at } 6 \mathrm{~h} \text {, no regrowth } \\
\text { after } 24 \mathrm{~h}\end{array}$ & ND \\
\hline A. baumannii (2) & 4 & Resistant & $\begin{array}{l}\text { Bactericidal at } 6 \mathrm{~h} \text {, no regrowth } \\
\text { after } 24 \mathrm{~h}\end{array}$ & ND \\
\hline A. nosocomialis (2) & 0.25 & $\begin{array}{l}\text { Sensitive, regrowth } \\
\text { after } 24 \mathrm{~h}\end{array}$ & $\begin{array}{l}\text { Bactericidal at } 6 \mathrm{~h} \text {, no regrowth } \\
\text { after } 24 \mathrm{~h}\end{array}$ & ND \\
\hline A. nosocomialis (2) & 4 & Resistant & Synergistic, no regrowth after $24 \mathrm{~h}$ & Synergistic no regrowth after $24 \mathrm{~h}$ \\
\hline A. lowffii (1) & 4 & Resistant & Not synergistic, regrowth after $24 \mathrm{~h}$ & Synergistic no regrowth after $24 \mathrm{~h}$ \\
\hline A. junii (1) & 2 & Resistant & Synergistic, no regrowth after $24 \mathrm{~h}$ & Synergistic no regrowth after $24 \mathrm{~h}$ \\
\hline A. haemolyticus (1) & 0.25 & $\begin{array}{l}\text { Sensitive, regrowth } \\
\text { after } 24 \mathrm{~h}\end{array}$ & Bactericidal, no regrowth after $24 \mathrm{~h}$ & ND \\
\hline
\end{tabular}

$N D$ not done

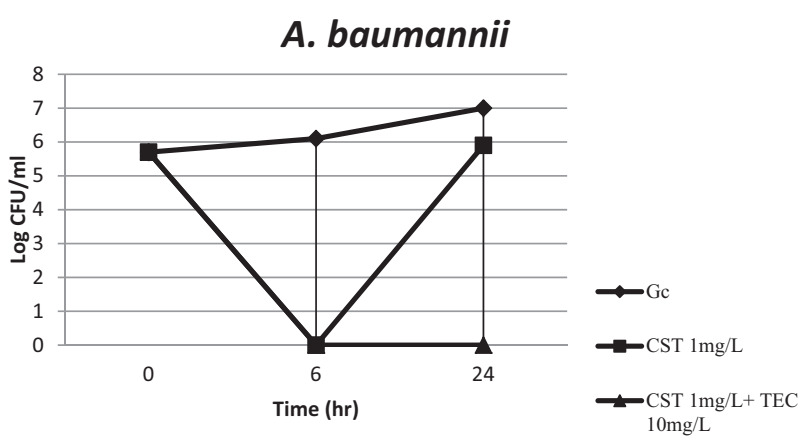

Fig. 1 Time-kill assay performed on 20 colistin susceptible $A$. baumannii isolates in the presence of $1 \mathrm{mg}^{-1}$ colistin (CST); and $1 \mathrm{mg} \mathrm{l}^{-1}$ colistin $+10 \mathrm{mg}^{-1}$ teicoplanin (CST/TEC). Gc growth control

The present study included only two colistin-resistant $A$. baumannii isolates where colistin-teicoplanin combination was bactericidal and synergistic against both isolates. Bae et al. [10] used higher concentrations to test the synergistic effect of colistin $\left(2 \mathrm{mg} \mathrm{l}^{-1}\right)$ and teicoplanin $\left(16 \mathrm{mg} \mathrm{l}^{-1}\right)$ against colistin-resistant $A$. baumannii isolates. However, their results depended on the method used, as synergy was higher using checkerboard methodology $(45 \%)$ versus multiple-combination bactericidal test $(88.88 \%)$. Bae et al. suggested that the combinations of glycopeptides and colistin may be effective regardless of its MICs, due to an adjuvant permeabilizing effect of colistin on the A. baumannii outer membrane (Fig. 1).

Bacterial regrowth was observed in this study. It may have several reasons in vitro including the use of sub-inhibitory concentration of antibiotics, emergence of resistant subpopulations, adherence of bacteria to the surface of the culture vessel and inactivation of the antibiotics in vitro are reasons for bacterial regrowth [11]. Moreover Owen et al. [12] observed that colistin was very active in the initial killing of colistin- susceptible strains of A. baumannii, even with $0.5 \times$ MIC. However, a modest positive post-antibiotic effect of colistin was noticed at higher concentrations $(\geq 16 \times$ MIC), which cannot be achieved in clinical practice and there was the substantial regrowth occurring at $24 \mathrm{~h}$ even at colistin concentrations up to $64 \times$ MIC.

Sanderink et al. [13] tested the efficacy of colistin-teicoplanin combinations in-vivo, the colistinteicoplanin increased the survival of mice infected with $A$. baumannii murine model of pneumonia. Sanderink et al., results suggest the possibility of using the colistin-teicoplanin combination in certain therapeutic deadlocks.

In the last decade, growing numbers of human infections caused by the non-baumannii Acinetobacter even MDR isolates causing hospital acquired infections have been reported globally. Even species that have less typically been linked to human disease including A. lwoffii, A. junii, and A. haemolyticus, were also reported [2, 14].

Non-baumannii Acinetobacter spp. have been shown to be resistant to colistin more often than A. baumannii. Several studies have reported a high level of resistance to colistin in $A$. nosocomialis compared with $A$. baumannii, ranging from 6.5 to $45.3 \%$ [15-17]. These findings are in accordance with findings of the present study as colistin resistance rate was $9.1 \%$ (2 out of 22) in A. baumannii while it was $40 \%$ (2 out of 4) in $A$. nosocomialis.

In the present study, the combination of colistin $1 \mathrm{mg}^{-1}$ and teicoplanin $10 \mathrm{mg} \mathrm{l}^{-1}$ was synergistic against all nonbaumannii isolates except one (A. lowffii), which was synergistic when teicoplanin concentration was increased to $20 \mathrm{mg}^{-1}$. In contrast to A. baumannii, the synergistic activity of the combination was not bactericidal against more than half of non-baumannii Acinetobacter isolates. Two of these isolates were A. nosocomialis and had a high colistin MIC value of $8 \mathrm{mg}^{-1}$. 
The difference in the bactericidal activity of the combination on A. baumannii and non-baumannii Acinetobacter could be attributed to the difference among Acinetobacter genospecies in their antimicrobial susceptibility [18, 19] and mechanisms of resistance to antimicrobial agents [18]. Moreover, in the case of non-baumannii Acinetobacter spp., information regarding the mechanisms of colistin resistance remains limited [20]. Although that A. lwoffii is usually susceptible to colistin, the present study included $A$. lwoffii clinical isolate that was colistin resistant Since A. lwoffii is not commonly found in clinical practice, this offered little opportunity for investigation thus its mechanism of resistance is still not clear, but maybe due to mutation in its lipopolysaccharide component.

In conclusion, the combination of colistin and teicoplanin was very effective in examined concentrations against all tested Acinetobacter spp. It is therefore recommended that clinical trials are conducted to clarify the in-vivo therapeutic potential of this combination.

Funding Research was funded by researchers themselves. Open access funding provided by The Science, Technology \& Innovation Funding Authority (STDF) in cooperation with The Egyptian Knowledge Bank (EKB).

\section{Compliance with ethical standards}

Conflict of interest The authors declare no competing interests.

Publisher's note Springer Nature remains neutral with regard to jurisdictional claims in published maps and institutional affiliations.

Open Access This article is licensed under a Creative Commons Attribution 4.0 International License, which permits use, sharing, adaptation, distribution and reproduction in any medium or format, as long as you give appropriate credit to the original author(s) and the source, provide a link to the Creative Commons license, and indicate if changes were made. The images or other third party material in this article are included in the article's Creative Commons license, unless indicated otherwise in a credit line to the material. If material is not included in the article's Creative Commons license and your intended use is not permitted by statutory regulation or exceeds the permitted use, you will need to obtain permission directly from the copyright holder. To view a copy of this license, visit http://creativecommons. org/licenses/by/4.0/.

\section{References}

1. Nasr P. Genetics, epidemiology, and clinical manifestations of multidrug-resistant Acinetobacter baumannii. J Hosp Infect. 2020;104:4-11.

2. Shin B, Park W. Antibiotic resistance of pathogenic Acinetobacter species and emerging combination therapy. J Microbiol. 2017;55:837-49.

3. Karakonstantis S, Saridakis I. Colistin heteroresistance in Acinetobacter spp.: systematic review and meta-analysis of the prevalence and discussion of the mechanisms and potential therapeutic implications. Int J Antimicrob Agents. 2020;56:106065.
4. Wareham DW, Gordon NC, Hornsey M. In vitro activity of teicoplanin combined with colistin versus multidrug-resistant strains of Acinetobacter baumannii. J Antimicrob Chemother. 2011;66:1047-51.

5. Clinical and Laboratory Standards Institute (CLSI). Performance standards for antimicrobial susceptibility testing. 29th ed. Wayne, PA: Clinical and Laboratory Standards Institute; 2019.

6. Carretto E, Brovarone F, Russello G, Nardini P, El-Bouseary MM, Aboklaish AF, et al. Clinical validation of SensiTest colistin, a broth microdilution-based method to evaluate colistin MICs. J Clin Microbiol. 2018;56:e01523-17.

7. Clinical and Laboratory Standards Institute (CLSI). Methods for determining bactericidal activity of antimicrobial agents: approved guideline M26-A. Wayne, PA: Clinical and Laboratory Standards Institute; 1999.

8. Landersdorfer CB, Nation RL. Colistin: how should it be dosed for the critically ill? Semin Respir Crit Care Med. 2015;36:126-35.

9. Brink AJ, Richards GA, Cummins RR, Lambson J. Recommendations to achieve rapid therapeutic teicoplanin plasma concentrations in adult hospitalised patients treated for sepsis. Int $\mathbf{J}$ Antimicrob Agents. 2008;32:455-8.

10. Bae S, Kim MC, Park SJ, Kim HS, Sung H, Kim MN, et al. In vitro synergistic activity of antimicrobial agents in combination against clinical isolates of colistin-resistant Acinetobacter baumannii. Antimicrob Agents Chemother. 2016;60:6774-9.

11. Pankey GA, Ashcraft DS. In vitro synergy of ciprofloxacin and gatifloxacin against ciprofloxacin-resistant Pseudomonas aeruginosa. Antimicrob Agents Chemother. 2005;49:2959-64.

12. Owen RJ, Li J, Nation RL, Spelman D. In vitro pharmacodynamics of colistin against Acinetobacter baumannii clinical isolates. J Antimicrob Chemother. 2007;59:473-7.

13. Sanderink D, Cassisa V, Chenouard R, Mahieu R, Kempf M, Dubée V, et al. Colistin-glycopeptide combinations against multidrug-resistant Acinetobacter baumannii in a mouse model of pneumonia. Future Microbiol. 2019;14:581-6.

14. Fitzpatrick MA, Ozer E, Bolon MK, Hauser AR. Influence of ACB complex genospecies on clinical outcomes in a U.S. hospital with high rates of multidrug resistance. J Infect. 2015;70:144-52.

15. Huang L, Chen TL, Lee YT, Lee MH, Kuo SC, Yu KW, et al. Risk factors for imipenem-nonsusceptible Acinetobacter nosocomialis bloodstream infection. J Microbiol Immunol Infect. 2014;47:311-7.

16. Lee YC, Huang YT, Tan CK, Kuo YW, Liao CH, Lee PI, et al. Acinetobacter baumannii and Acinetobacter genospecies $13 \mathrm{TU}$ and 3 bacteraemia: comparison of clinical features, prognostic factors and outcomes. J Antimicrob Chemother. 2011;66:1839-46.

17. Yang YS, Lee YT, Tsai WC, Kuo SC, Sun JR, Yang CH, et al. Comparison between bacteremia caused by carbapenem resistant Acinetobacter baumannii and Acinetobacter nosocomialis. BMC Infect Dis. 2013;13:311.

18. Chuang YC, Sheng WH, Li SY, Lin YC, Wang JT, Chen YC, et al. Influence of genospecies of Acinetobacter baumannii complex on clinical outcomes of patients with acinetobacter bacteremia. Clin Infect Dis. 2011;52:352-60.

19. Lin YC, Sheng WH, Chang SC, Wang JT, Chen YC, Wu RJ, et al. Application of a microsphere-based array for rapid identification of Acinetobacter spp. with distinct antimicrobial susceptibilities. J Clin Microbiol. 2008;46:612-7.

20. Lee YT, Sun JR, Wang YC, Chiu CH, Kuo SC, Chen TL, et al. Multicentre study of risk factors for mortality in patients with Acinetobacter bacteraemia receiving colistin treatment. Int $\mathrm{J}$ Antimicrob Agents. 2020;55:105956. 